\title{
¿Existe algo como un "problema de los barrios sensibles"? Retorno sobre una categoría de acción pública ${ }^{1}$
}

\section{Is There an "Underprivileged Areas Problem" in France? Reflections on a Category of Public Action}

\section{Y a-t-il un "problème des quartiers sensibles"? Retour sur une catégorie d'action publique}

\author{
Sylvie TISSOT \\ Université Vincennes Saint Denis Paris 8 \\ sylvie.tissot@univ-paris8.fr
}

Recibido: 13 de enero de 2013

Aceptado: 14 de marzo de 2013

\begin{abstract}
Resumen
Los disturbios de noviembre 2005 en Francia han reactivado los debates sobre la situación de los barrios llamados sensibles. Este artículo aporta una contribución original a dichos debates. En vez de analizar lo que ha ocurrido en estos espacios, estudio cómo este problema social ha sido construido, hecho público, y cómo se ha convertido en un objeto público desde el final de los años 1980. Muestro que la focalización sobre estos barrios desfavorecidos no se debe simplemente a problemas tales como el paro, la pobreza o la delincuencia juvenil. Dicha focalización responde a un reajuste de la acción pública centrado en unos espacios particulares en vez del territorio nacional en conjunto, y en la cuestión del vínculo social en vez de atender a la realidad económica. Esta aproximación constructivista permite comprender cómo hombres y mujeres políticos, expertos así como funcionarios, han asociado la cuestión de los "barrios sensibles" a ciertos problemas (falta de comunicación y debilitamiento del vínculo social) al mismo tiempo que han ignorado otros (como la discriminación social).
\end{abstract}

Palabras clave: Barrios desfavorecidos, problema social, Estado del bienestar, constructivismo, activismo.

\begin{abstract}
The outbreak of the November 2005 riots in France brought new attention to debates over the situation of underprivileged areas. This article offers a new perspective on this question. Rather than analyzing what happened in these territories, I examine how this social problem was constructed, publicized, and thus became an object of public policy since the end of the 1980s. I show that the political focus on underprivileged areas was not primarily or only an

${ }^{1}$ Artículo traducido con el permiso de Berghahn Journals, from French Politics, Culture \& Society, 2006, 24: 3. Sylvie Tissot, "Y a-t-il un problème des quartiers sensibles? Retour sur une catégorie d'action publique".
\end{abstract}


effect of increasing problems on the ground, such as unemployment, poverty or juvenile delinquency. The focus instead resulted from and contributed to a fundamental restructuring of the French Welfare State, by authorizing a recentering of public action on specific urban spaces - rather than across the nation - and on social ties, rather than economic reality. This constructivist study seeks to understand why politicians, experts or civil servants have associated the question of "underprivileged areas" with certain problems (like lack of communication and the weakening of social ties) while ignoring others (such as ethnic discrimination).

Keywords: Underprivileged areas, Social problem, Welfare state, Constructivism, Activism.

\section{Résumé}

Les émeutes de novembre 2005 en France ont relancé les débats sur la situation des quartiers dits sensibles. Cet article apporte une contribution originale à ces débats. Plutôt que d'analyser ce qui s'est passé sur ces espaces, j'étudie la manière dont ce problème social a été construit, publicisé et comment il est devenu un objet de politique publique depuis la fin des années 1980. Je montre que la focalisation sur ces quartiers défavorisés n'est pas la simple ou la seule conséquence de problèmes tels que le chômage, la pauvreté ou la délinquance juvénile. Cette focalisation correspond à un recentrage de l'action publique sur des espaces particuliers plutôt que sur l'ensemble du territoire national et sur la question du lien social plutôt que sur la réalité économique. Cette approche constructiviste permet de comprendre comment des hommes et femmes politiques, des experts ainsi que des fonctionnaires ont associé la question des « quartiers sensibles » à certains problèmes (manque de communication et affaiblissement du lien social) tout en en ignorant d'autres (comme la discrimination raciale).

Mots-clé: Quartiers défavorisés, problème social, État-providence, constructivisme, activisme.

Referencia normalizada: Tissot, S. (2013) ¿Existe algo como un “problema de los barrios sensibles"? Retorno sobre una categoría de acción pública, en Revista de Antropología Social, 22: 137-153

SUMARIO: 1. Política de los "barrios sensibles": reformar el Estado planificador. 2. Una institucionalización "política". 3. La alianza con los "modernizadores" de la acción pública. 4. Una política encuadrada del "vínculo social". 5. Referencias bibliográficas.

La voluntad, claramente loable, de ir a conocer las cosas personalmente, y de modo cercano, lleva a veces a buscar los principios explicativos de las realidades observadas donde no están —no todos, en cualquier caso-, es decir en el lugar mismo donde se observan: así, no cabe dudar de que la verdad de lo que ocurre en los "suburbios difíciles" no se encuentra en estos lugares habitualmente olvidados que surgen de vez en cuando en el primer plano de la actualidad. (Bourdieu, 2006)

Aunque las interpretaciones diverjan, todo el mundo parece concordar en que existe un grave problema en los "barrios sensibles" en Francia; las revueltas de los 
suburbios en noviembre del 2005 parecen aportar la última prueba de ello. No hay duda, en efecto, de que estos barrios de protección oficial construidos precipitadamente a partir de los años 1950 para responder a las necesidades urbanísticas durante los Treinta Gloriosos ${ }^{2}$, han sufrido cambios nuevos y, a menudo, preocupantes. Después de la salida de numerosas familias de clases medias, animadas a acceder a la propiedad privada, la población no ha dejado, de manera global, de empobrecerse, mientras que los extranjeros, que habían estado hasta entonces casi excluidos de los alojamientos sociales, entraban en ellos de manera masiva. Estos grandes conjuntos urbanísticos se han ido degradando al tiempo que desde principios de 1980 hasta noviembre 2005, estallaban "revueltas" en estos barrios, que revelaban un fuerte contencioso de los jóvenes para con la policía. Este artículo pretende ser una contribución a las reflexiones que se han desarrollado después de noviembre del 2005 para comprender las razones que explican semejante revuelta, pero sin dejar de interrogarse precisamente sobre la existencia de un "problema de los barrios sensibles". ¿Significa esto que no hay "problemas"? Lejos de relativizar la urgencia y la gravedad de la situación, quisiéramos mostrar lo que está en juego en esta categoría de "barrio sensible" y en su construcción como "problema social".

Si se toma aquí como objeto la categoría de "barrio sensible" y no los territorios en sí mismos, es porque, desde nuestro punto de vista, no se puede comprender la situación de los habitantes de los barrios de protección oficial — se rebelen o nosin reconsiderar la definición que se da al "problema de los suburbios" desde hace veinte años y las soluciones a las que ha abocado esta problematización. Aunque un primer impulso nos incitaría a ir sobre el "terreno" para comprender las evoluciones actuales, limitar la investigación a estos territorios — como explica Bourdieu en la cita que inicia el texto- es insuficiente: es preciso también estudiar los diagnósticos que han sido formulados sobre ellos, las elecciones hechas para ellos, los dispositivos que les han transformado, las medidas, tanto las tomadas como las rechazadas, que han influenciado su porvenir: todo esto produce una realidad, cuya comprensión requiere que se investigue en el seno de universos sociales diversos, a veces incluso muy alejados del mundo de los "suburbios". Es lo que haremos en este artículo, aportando algunos elementos de análisis sobre la génesis del "problema de los barrios sensibles"

Al desviar de este modo la mirada de los territorios que están regularmente en primera plana de la actualidad, quisiéramos mostrar la pertinencia de la aproximación constructivista en sociología(Blumer, 1971), que no pretende evaluar ni medir la realidad de los problemas sociales sino tomar como objeto su construcción. ¿Qué ha sido decisivo en la construcción de los "barrios sensibles" entendidos como categoría de acción pública? Nada menos que un re-encuadre y una redefinición de las políticas sociales en torno a un cierto tipo de intervención. La focalización en los "barrios sensibles" durante los años 1985-95 suscitó, en efecto, un conjunto de

2 [NdT] La expresión designa el período de 30 años de auge económico desde el final de la Segunda Guerra Mundial hasta el primer choque petrolífero en 1973.

${ }^{3}$ Este artículo retoma algunos elementos desarrollados en Tissot (2007). 
dispositivos que descansaba sobre un vocabulario relativamente coherente y ampliamente divulgado, y que constituía un verdadero programa: promoción de la "participación de los habitantes", restauración del "diálogo" y de la "confianza", realización de "proyectos" con un espíritu "ciudadano", valorización de la "proximidad" y de lo "local" como garantía de eficacia y de democracia, práctica de la "transversalidad" y de la "concertación" entre partenaires. Es así como se constituyeron equipos en varios centenares de municipios a lo largo y ancho de Francia para implicar a los habitantes en las operaciones de rehabilitación de las barriadas [cité] de HLM ${ }^{4}$, para organizar lugares de encuentro y de discusión sobre los barrios de protección oficial — como los consejos de barrios—- así como para dinamizar y organizar la vida asociativa. Pero más allá de estos dispositivos, lo que se desarrolló en los debates públicos de los años 1985-95 es toda una representación de estos barrios. Mientras se convierten en tema de debates, reportajes, libros, coloquios, y en el símbolo de una nueva "cuestión social", estos territorios no son aprehendidos en efecto a través del estatus social de sus habitantes —ya se hable de clases populares o de clase obrera-, sino más bien a través del prisma de sus "orígenes", nacionales, culturales o "étnicos" - percibidos como problemáticos y/o amenazantes en vez de considerarlos como fuentes de problemas específicos para los habitantes en cuestión-, y sobre todo centrándose en la anomia y la falta de vínculo social que reinarían allí.

Por qué la categoría de "barrio sensible" se ha impuesto en la acción pública y por qué se ha impuesto sobre la base de un diagnóstico centrado en torno al tema del "vínculo social", mientras que hubieran podido plantearse cuestiones y aproximaciones totalmente diferentes: en torno a las transformaciones del sistema económico, a las desigualdades sociales crecientes o también a las persistentes formas de discriminación. Quisiéramos responder aquí a esta cuestión, echando una mirada retrospectiva hacia los recorridos de los actores que han promovido esta categoría, y los universos sociales en los que se han movido activamente. Dos fenómenos nos parecen decisivos. La crítica del Estado planificador francés, surgido tras la segunda guerra mundial, ha hecho posible que emerjan otras maneras de actuar y, en particular, la institucionalización de una política de "participación de los habitantes". Por otra parte, la emergencia de este nuevo sentido común en torno a los "barrios sensibles" debe mucho a los procesos de reconversión militante y profesional de un grupo de jóvenes diplomados procedentes de la ola crítica del mayo del 68 .

\section{Política de los "barrios sensibles": reformar el Estado planificador}

La noción de "barrio sensible" —o también de "barrios difíciles" o "barrios con dificultades" - se ha impuesto en el debate público francés al final de los años 1980, y más precisamente, en la acción pública, con ocasión de la llamada Política de la Ciudad [de la ville]. La Política de la Ciudad, cuyo nacimiento se fecha habitualmente en 1977 con los dispositivos Habitat y Vida social [Habitat et vie sociale], se amplia a lo largo del decenio siguiente, con la creación de la Comisión nacional de desarrollo social de los barrios [Commission nationale de développement social des

${ }^{4}[\mathrm{NdT}] \mathrm{HLM}$ es el organismo estatal encargado de las viviendas de protección oficial. 
quartiers - CNDSQ] en 1982, la puesta en marcha de las convenciones Desarrollo social de los barrios [Développement social des quartiers -DSQ] a partir de 1984, y luego con la creación de la Delegación interministerial de la ciudad [Délégation interministérielle de la ville -DIV] en 1988, y del Ministerio de la ciudad en 1991, que dirigen unos nuevos dispositivos llamados "contratos de ciudad". Mediante estos contratos, se han desbloqueados créditos destinados a financiar la rehabilitación de las barriadas [cités $H L M$ ], pero también para implementar, a nivel local, un acompañamiento social destinado a suscitar la "participación de los habitantes" y a desarrollar la vida asociativa en los barrios. Al intervenir de manera directa en unos centenares de barrios de protección oficial, el objetivo defendido por la Política de la Ciudad ha sido, pues, el de rehabilitar las barriadas [cités HLM] más estropeadas pero con el objeto de revitalizar la vida social en dichos territorios. En efecto, tal como hemos señalado, la focalización sobre los "barrios sensibles" no desemboca únicamente en una territorialización de la acción pública, sino al mismo tiempo en orientarla hacia una cuestión considerada prioritaria: la vida social en estos territorios.

Esta acción está directamente concebida como una reacción a la del Estado que impulsa, organiza, y planifica la construcción de los grandes conjuntos de viviendas durante las décadas de la post-guerra de un modo fuertemente intervencionista y centralista. En efecto, los impulsores de la Política de la Ciudad van a promover, en nombre del "entorno vital" [cadre de vie], una acción "global" de "rehabilitación", que implica a las colectividades locales y funciona sobre la base de una "participación" de los habitantes. Pero pueden hacerlo sólo porque, desde los años 1960, la intervención estatal instaurada después de la Segunda Guerra Mundial ha sido objeto de virulentas críticas. La denuncia de la normalización y del autoritarismo tecnocrático, particularmente fuerte en el seno de los movimientos intelectuales y políticos de izquierda - inspirados entre otras cosas por el pensamiento de Michel Foucault-, se redobla gracias a una crítica más liberal desarrollada entre otros por el presidente Giscard d'Estaing a partir de 1974. Es entonces cuando, al calor de las crisis petrolíferas, la intervención del Estado se encuentra fuertemente replanteada en nombre del libre funcionamiento de las fuerzas del mercado, con respecto, en particular, al ámbito de la vivienda, objeto emblemático del Estado planificador. Se apuntan especialmente las operaciones "bulldozers" llevadas a cabo en el centro de las ciudades y estos famosos "conjuntos urbanísticos" [grands ensembles]— de los cuales se denuncian tanto el carácter inhumano de su arquitectura como su mórbido entorno. Se replantean entonces radicalmente los principios sobre los cuales descansaban las políticas de la vivienda: la afirmación del Estado como representante y promotor del interés general y la celebración de la planificación urbana. Dicho cuestionamiento está reforzado por la descentralización de 1983 - y la transferencia a los municipios de las competencias urbanísticas - y luego por la progresiva concentración de las políticas de la vivienda sobre las poblaciones más desfavorecidas en detrimento de una acción directa para construir y organizar un verdadero mercado de la vivienda (Coing H. y Topalov C., 1996). Así, desde la mitad de los años 1970, 
un amplio movimiento en favor de la rehabilitación ha podido desarrollarse como reacción frente a un modelo planificador en crisis.

En esta época es cuando los encargados de las administraciones sucesivas de la Política de la Ciudad van a empezar a imponerse. Proceden, en su mayoría, del ámbito de los estudios urbanos nacido hace dos décadas dentro de la órbita del Ministerio de Fomento [Ministère de l'Équipement]. Al desarrollar su actividad en unos servicios de estudios creados para poner en marcha la ordenación de las ciudades, ocupan unas posiciones relativamente dominadas dentro de la administración, en particular en relación al cuerpo de los Ingenieros de Caminos que constituyen las puntas de lanza del Estado planificador. La Política de la Ciudad va a ofrecerles un modo de reciclaje profesional, hecho necesario debido a la reducción del mercado de los estudios urbanos, antes alimentado por la planificación estatal. Además de estas oportunidades oficiales que, de hecho, implican poca o ninguna revalorización, la Política de la Ciudad es también, para estos actores, parte activa de la ola crítica de mayo 1968, un lugar de reconversiones militantes en una época — la segunda mitad de los años 1970 - en la que se reduce otra oferta — la de los movimientos militantes. El compromiso con los "barrios", percibido como eficaz y tangible a corto plazo - ya que se apoya en la acción pública-, va a constituir, después del militantismo en partidos o asociaciones de izquierda y de extrema izquierda, otro tipo de compromiso. Es el caso, por ejemplo, de este encargado reclutado en 1991 en la Delegación interministerial para la ciudad. Nacido en 1951, es estudiante al principio de los años 1970 en el Instituto de Estudios Políticos de Paris al tiempo que milita casi a tiempo completo en la organización trotskista, la Liga comunista revolucionaria. Al haber renunciado a presentarse a la oposición para entrar en el Ministerio de Asuntos Exteriores [Quai d'Orsay] y por lo tanto a seguir la carrera diplomática en la que pensaba, entra en la vida activa con unas habilidades que reconvierte eficazmente en el puesto que saca a principios de los años 1980: director de gabinete del alcalde de una ciudad mediana. Su trabajo consiste precisamente en establecer contactos con los gabinetes ministeriales, utilizar las relaciones políticas para presionar a los servicios descentralizados del Estado y, de este modo, hacer progresar unos proyectos favorables para la ciudad. Esto le lleva a ocuparse de la Política de la Ciudad, antes de ser reclutado a nivel nacional, en la DIV. En estos puestos que requieren habilidades de redacción y para relacionarse, pone en valor tanto un capital escolar como la posesión de un léxico y de un sentido práctico político.

Si estos procesos de reconversión son tan importantes, no se debe, por consiguiente, únicamente al hecho de que la Política de la Ciudad se presente como un tipo de acción profesional, alternativo al compromiso, sino porque es vivida de un modo "comprometido". Lo es también porque están reconvertidas unas competencias acumuladas en el curso de una experiencia militante, y, para muchos actores de la Política de la Ciudad, mediante luchas ligadas a las políticas urbanas: movimientos de protesta en contra de la renovación urbana en los barrios céntricos de la ciudad, como el distrito XIII de Paris, o en otros barrios destinados a ser destruidos como la Estación-Alma en Roubaix, ciudad del norte de Francia, o también en 
barrios de protección oficial ${ }^{5}$. Después de estas experiencias se podrá así reivindicar una habilidad específica, fundada en la capacidad para apoyar y organizar la "participación de los habitantes" en los "barrios". Esta habilidad va a ser valorizada en la Política de la Ciudad, bien sea por la administración central que recluta y pide numerosos informes durante los años 1980, o bien por los municipios necesitados de personal y de estudios sobre las cuestiones urbanas - de las que están encargados como consecuencia de la descentralización- $\mathrm{y}$, más precisamente para dirigir los dispositivos de la Política de la Ciudad. Por lo tanto lo que explica la institucionalización de la categoría "barrios sensibles" son a la vez unos acontecimientos específicos - la crisis del Estado planificador y la llegada de la Izquierda al poder en 1981 - y las propiedades sociales de actores dispuestos a innovar y que están disponibles para hacerlo.

Sin embargo, el sentido que se da a la categoría no es unívoco en la medida en que se desarrollan, entre los promotores de la Política de la Ciudad, luchas en torno a la definición legítima del "problema de los barrios sensibles". Y se asiste, durante el periodo 1985-1995, a un giro muy decisivo que sigue dos vías: un cambio de mirada sobre los barrios y un 'nuevo enfoque' [recadrage] del problema. La cuestión de los "barrios sensibles" se impone inicialmente sobre la base de un diagnóstico que valora los barrios de protección oficial, descritos como los lugares de una rehabilitación por fin preocupada por el "entorno vital" [cadre de vie] y por los habitantes, pero sobre todo como lugares donde fuera factible una renovación de la vida política y ciudadana: es lo que atestiguan los artículos de la revista de Política de la Ciudad, Ensembles ${ }^{6}$, entre los cuales un gran número están dedicados a experiencias singulares llevadas a cabo bajo la iniciativa de habitantes de las barriadas [cités]. Progresivamente, el término "barrio sensible" va a designar unos territorios marcados negativamente, descritos como lugares donde se acumulan los "problemas sociales", que necesitan menos el desarrollo de una acción autónoma que la intervención de especialistas. De tal modo que la dimensión contestataria, muy presente en la llamada a la movilización de los habitantes, se desdibuja en favor de una acción pública racionalizada y "profesionalizada". Paralelamente, se asiste, durante los primeros años 1990, a una mayor abstracción, imponiéndose el "barrio sensible" como una categoría genérica de aprehensión de los problemas sociales, estrechamente relacionada con la noción vaga y consensual de "exclusión" y, de manera concomitante, con la cuestión del "vínculo social", en detrimento de las cuestiones relativas a las instalaciones o de la construcción propiamente dicha, de los problemas económicos o, también, del de la discriminación.

Se podría explicar más sencillamente esta evolución por la transformación de estos barrios en sí mismos, cuyas revueltas en los años 1990 y 1991 hubieran revelado los crecientes problemas. No obstante, los discursos que se imponen en el espacio público no se limitan a retraducir una realidad "objetiva". Dichos discursos

${ }^{5}$ Sobre la movilización de la Estación-Alma, ver Christian Bachmann y Nicole Leguennec (1996). Sobre las reconversiones de los militantes, véase Tissot (2005).

${ }^{6}[\mathrm{NdT}]$ Ensembles significa Juntos.

${ }^{7}$ Sobre esta noción, véase Fassin (1996). 
ponen de manifiesto sobre todo el hecho de que una opción se impone: la redirección hacia la cuestión del "vínculo social", definido como falta de diálogo y de comunicación. Este proceso es lo que se quisiera explicar en lo que sigue, dirigiendo la mirada hacia las condiciones sociales de emergencia de la categoría "barrio sensible" como categoría de acción pública.

\section{Una institucionalización "política"}

La primera explicación de este reajuste remite al hecho de que esta institucionalización de la categoría se opera primero sobre la base de una alianza con la izquierda gubernamental en el poder a lo largo de la década de 1980. En efecto, los fundadores de la Política de la Ciudad actúan, al final de los años 1970 y sobre todo al principio de los 80, a partir de posiciones marginales en el seno del mundo de la administración. La Delegación interministerial para la ciudad debe inicialmente conformarse con líneas de créditos procedentes de diferentes ministerios, incluido el de Fomento, y sólo es a partir de 1993 cuando se la dota de un presupuesto propio. Los empleados de las administraciones de la Política de la Ciudad que se van sucediendo entre 1981 y 1990 son, además, poco numerosos — entre quince y treinta y cinco titulares - . Pero ante todo, formada por agentes en su mayoría contratados, esta administración comprende un número reducido de funcionarios. Las estructuras de la Política de la Ciudad padecen así una falta, entre sus filas, de actores que dispongan de bastante autoridad en el campo administrativo, y en particular, de funcionarios salidos de las grandes escuelas, como ingenieros de Caminos [Ponts et Chaussées] o alumnos de la $E N A$ - Escuela nacional de administración-.

De este modo, desde la institucionalización de la Política de la Ciudad al principio de los años 1980, los responsables de los proyectos topan con una multitud de obstáculos: carentes de un presupuesto propio, sin títulos administrativos, se encuentran sin los instrumentos necesarios para la actividad de cualquier administración, es decir el control del dinero público y la producción de instrucciones. Además, la Política de la Ciudad, que se quiere transversal al estar territorializada, topa, en cada una de las esferas donde pretende actuar — sea la vivienda, la salud, la acción social, o la educación - , con un ámbito de competencias ya constituido. Así, los encargados de la DIV no dejan de enfrentarse con distintos ministerios, sin constituir además unos interlocutores legítimos para los sub-directores o los jefes de servicio con los cuales tienen que negociar. Frente a ellos, no se encuentran únicamente unos titulares de la función pública, sino miembros de las grandes escuelas, o agentes que han ganado las prestigiosas oposiciones de los ministerios. Unos funcionarios para quienes responder a una solicitud de colaboración, o incluso otorgar una cita, obedece a unas estrictas reglas de equivalencia dentro de la jerarquía administrativa, que 'transgreden' muchos encargados de la DIV.

Los actores de la Política de la Ciudad van, pues, a imponerse sobre la base de una alianza de facto con los partidos de la izquierda gubernamental. Esta alianza se explica en primer lugar por el compromiso histórico de varios alcaldes con procesos experimentales de "democracia participativa", de apertura a la "sociedad civil", en particular en los barrios de viviendas de protección oficial. Uno de estos concejales 
socialistas, el alcalde de Grenoble, Hubert Dubedout es por ejemplo encargado en 1981 de redactar un informe previo a la creación de la CNDSQ (Dubedout, 1983). Los vínculos entre los promotores de una acción sobre "los barrios" y el Partido Socialista no van a dejar de reforzarse: no solamente porque el Presidente de la República y el Primer Ministro, Michel Rocard, van a "apostar" después de la revuelta de Vaulx-en-Velin de 1990, por la Política de la Ciudad; sino también por el hecho de que, para aquellos primeros, las amenazas de desaparición que hacen presagiar los posibles retornos de la derecha (antes de 1986 y, luego, antes de 1993) favorecen su acercamiento al Partido Socialista.

Procedentes del ámbito de los estudios urbanos, los promotores de esta política han, en efecto, impuesto su "causa" en la administración, destacando la necesidad de nuevas consignas y de nuevos métodos: "participación", "concertación", y "acción transversal" para abordar la cuestión de los barrios de protección oficial. Es la llegada de la Izquierda al poder en 1981 lo que crea tales oportunidades. No obstante, sin anclaje fuerte en la administración, estos posicionamientos no bastan para escapar del riesgo de la alternancia, de tal modo que la carrera de estos encargados va a depender cada vez más estrechamente de la Política de la Ciudad y, por lo tanto, de la victoria del partido Socialista en 1988. La trayectoria de un encargado de misión de la DIV es particularmente emblemática. Muestra en efecto el impacto que han tenido las transformaciones de las políticas urbanas y del papel desempeñado por el Ministerio de Fomento, así como los constreñimientos de la institucionalización cuando de imponerse en la administración se trata.

Nacido en 1934, este joven licenciado en derecho aprovecha la oferta hecha a diplomados, procedente de oficinas de estudios urbanos. Los puestos sucesivos que ocupa son reveladores de las carreras profesionales que eran entonces posibles en este ámbito de estudios impulsado por los poderes públicos. Se le contrata en oficinas para-públicas y, luego crea su propia estructura, sin dejar de trabajar varias veces en el Ministerio de Fomento. En 1978, continuando como contratado, se le nombra director del gabinete de urbanismo en el Ministerio de Fomento. A este título, participa en las reuniones de trabajo de la comisión Dubedout creada después de los sucesos de las Minguettes ${ }^{8}$ en 1981 para reflexionar sobre la creación de nuevos dispositivos en los barrios desfavorecidos. Los años que siguen a la llegada de los socialistas muestran cómo, en el momento en el que este encargado de proyectos se involucra en la cuestión de los "barrios", se combinan imperativos profesionales y lógicas políticas. Es en particular porque es miembro del PSU (Partido Socialista Unificado) desde $1968^{9}$ que entra, en 1983, a formar parte del gabinete de la ministra de medioambiente, Huguette Bouchardeau. El director de gabinete de ésta es un antiguo secretario nacional del PSU y un amigo. Se convierte entonces en representante del Ministerio de Fomento en la Comisión nacional de desarrollo

${ }^{8}[\mathrm{NdT}]$ Se refiere a unas revueltas que tuvieron lugar en la barriada de las Minguettes, en Vaulx-en-Velin.

${ }^{9}$ El PSU constituye una corriente importante de la izquierda francesa en los años 1960 y 1970. Nació en abril de 1960 a partir de un movimiento de oposición a la guerra de Argelia y al apoyo de la SFIO al golpe de estado de De Gaulle en 1958. 
social de los barrios. En 1986, después de la vuelta de la derecha al poder, el antiguo militante del PSU tiene que salir del gabinete del Ministerio de Medioambiente y se le recoloca, al volver a Fomento, en un puesto relegado. Acepta entonces con entusiasmo la oferta que se le hace de incorporarse a la administración de la Política de la Ciudad. De ahora en adelante, la vuelta a un cargo valorizante está subordinada a su compromiso con la Política de la Ciudad que, en sí-misma, tiene poca probabilidad de cobrar nuevamente interés sin la victoria del Partido Socialista en 1988.

Inicialmente, la Política de la Ciudad es una política pública que fue posible acometer cuando la Izquierda estaba en el poder. A partir de 1986, y para muchas personas, se ha convertido en un refugio en un período caracterizado por un revés político (la co-habitación) y, al mismo tiempo, en un objeto sobre el cual se van adquiriendo competencias que se podrán hacer valer cuando retorne la izquierda. Así vemos lo que lleva a los "reformadores" de los barrios a acercarse a la izquierda gubernamental, haciendo más difícil la promoción de una política que no cuadrara con las orientaciones tomadas por el Partido Socialista a partir de 1983, a saber el giro hacia el rigor y la puesta en marcha de políticas de desinflación competitiva ${ }^{10}$. Y, de hecho, la reivindicación de créditos específicos para los "barrios" o, más adelante, los pronunciamientos a favor de un "Plan Marshall para los suburbios", no se harán nunca dentro de un marco de pensamiento keynesiano, es decir que pretendiera obtener efectos benéficos de una recuperación a nivel nacional, sino más bien con el objetivo de implantar unas acciones localizadas, que remedien supuestamente, a esta escala, el "problema de los barrios". Vemos así cómo la institucionalización de una acción sobre los "barrios" y el debilitamiento del Estado social han ido a la par. Aunque la Política de la Ciudad se traduce en financiaciones suplementarias - pero justo en el momento en el que las políticas de derecho común en los barrios populares, en particular en materia educativa, son objeto de severos recortes-, se asemeja más a la implementación, desde una óptica liberal, de una red de seguridad para los más desfavorecidos que a una acción redistributiva.

\section{La alianza con los "modernizadores" de la acción pública}

La frágil posición de la DIV recomienda varias estrategias: la búsqueda de un eco mediático - como atestigua la llegada de Bernard Tapie al Ministerio de la Ciudad en 1993, hombre de negocios y personalidad política que ha integrado hasta el más alto nivel las reglas de la comunicación política-, el llamamiento a los intelectuales, la búsqueda de una mayor racionalización, pero también la alianza con otros reformadores. Dicha alianza va a tener un máximo impacto sobre la reformulación del "problema de las barriadas" y su reajuste, no únicamente en torno a la cuestión del "vínculo social", sino también a la reforma de los servicios públicos en las "barriadas sensibles".

En efecto, se encuentran potentes aliados entre aquellos que, en la misma época en la que se inventa la Política de la Ciudad, reflexionan sobre la "modernización del Estado". Las críticas desarrolladas, desde el final de la década de 1960, en contra

\footnotetext{
${ }^{10}$ Con respecto a este giro, véase Jober (1994).
} 
del Estado del bienestar al que se reprocha su ineficacia, desembocan en efecto, a partir del giro hacia el rigor en 1983, en una serie de transformaciones ${ }^{11}$, que van a favorecer el reforzamiento continuado de las posiciones de los reformadores del Estado. La modernización de los servicios públicos se convierte en la consigna de los gobiernos, tanto de izquierda como de derecha. Sin embargo, dicho discurso modernizador adquiere en Francia una forma particular. En Gran Bretaña, bajo el impulso de Margaret Thatcher o, en Estados Unidos, con el de Ronald Reagan, se oponen explícitamente las leyes del mercado y de la competencia a la ineficacia de la acción política. En Francia, en los debates y las declaraciones políticas que se suceden en el momento en el que Michel Rocard, en 1988, hace un llamamiento en favor de la "renovación de los servicios públicos" (es decir cuando se relanza la Política de la Ciudad con la creación de la DIV), los reformadores se posicionan del lado de la "democracia".

Aparecen entonces una serie de términos que van a constituir unos puentes entre los reformadores del Estado y los de los barrios. La "democracia", la "ciudadanía", pero también la "proximidad" se convierten en las consignas de ambas reformas. Este encuentro funciona como una doble legitimación: la primera se vuelve más "social" y la segunda más "moderna". De hecho, a partir de 1993, la modernización se incorpora a las misiones de la Delegación Interministerial para la Ciudad. En el "expediente de recursos" [dossier-ressources] que edita este año para la preparación de los contratos del Onceavo Plan para la ciudad (1994-1998), la DIV menciona explícitamente este nuevo encargo: "La cuestión de la gestión de los territorios, de los necesarios procesos de modernización y de adaptación de las diferentes prestaciones públicas (arrendadores, servicios municipales, concesionarios, servicios públicos del Estado y demás colectividades...) será explícitamente tratada".

Atestiguada por los discursos ${ }^{12}$, esta circulación de los principios de legitimidad remite a una red que no queda limitada a los encargados de misión de la DIV sino que implica a unos actores que están a caballo entre el mundo de la investigación y el campo burocrático. Encontramos aquí la revista Esprit, revista intelectual para el gran público, marcada por el catolicismo de su fundador, y lugar de encuentro entre altos funcionarios, sindicalistas e intelectuales que intentan, en los años 1960, promover la emergencia de nuevas relaciones entre el Estado y la "sociedad civil". Estos contactos que ya existían van a multiplicarse con ocasión de encuentros y reflexiones sobre la Política de la Ciudad, en los cuales se plantea la relación entre la evaluación de las políticas públicas y las cuestiones urbanas.

El vínculo entre ambos movimientos de reforma está reforzado por un actor, Patrick Viveret, cuya trayectoria pone de manifiesto las propiedades sociales compartidas por numerosos "reformadores" de las "barriadas sensibles" (compromiso con la "Segunda-izquierda" [deuxième gauche], actividad intelectual, lazos estrechos con el mundo político-burocrático). Patrick Viveret es militante del PSU, y en 1975

${ }^{11}$ Sobre el tema de la historia de la reforma del Estado, consultar Dreyfus (2000).

${ }^{12}$ Sobre la producción de las relaciones que justifican la necesidad de servicios públicos específicos en las barriadas llamadas sensibles y sobre los presupuestos en los que aquella se basa, véase Siblot (2003). 
se convierte en redactor-jefe asalariado de una publicación de la central sindical CFDT. Viveret desempeña un papel activo en la reforma del Estado. Próximo a la corriente de Michel Rocard, de la que se convierte en uno de los teóricos, cuando éste último entra en el Partido Socialista en 1973, el Primer Ministro le confía, el 1988, el expediente de evaluación. Viveret se apodera de ello convirtiéndolo en motor de transformación de la acción pública, pero también movilizando todas las reflexiones acumuladas desde los años 1960 en el PSU, en particular la denuncia de la planificación tecnocrática y el principio de autogestión de los servicios públicos por los trabajadores y usuarios. Dichas consignas se traducen en el informe remitido por Viveret a Michel Rocard en 1989 evocando la "ciudadanía en una república" y la voluntad de "mejorar la calidad de nuestra vida democrática" pero también de actuar para "una mayor eficacia del Estado, y no con una lógica empresarial demasiado restrictiva" (Viveret, 1989; Spenlehauer, 1998). Es a partir de esquemas de pensamiento de este género como la Política de la Ciudad podrá reivindicar un método de acción pública particular, que se presenta como modelo de una reforma más general del Estado.

De tal modo que, aunque se oponen a una lógica demasiado "empresarial", los impulsores de la Política de la Ciudad no dejan, sin embargo, de ratificar la idea de una reforma necesaria del Estado. Como hemos visto, esta voluntad de reforma está presente entre los defensores de las "barriadas" desde los inicios. Pero lo que es nuevo para estos antiguos militantes, es que esta reforma va a sustentarse, de ahora en adelante, en una desconfianza creciente hacia los habitantes acusados de complacerse con un régimen asistencial [assistanat], y hacia la presencia estatal como tal, a la que se reprocha alimentar dicho régimen. Vemos como la adhesión a la retórica "modernizadora" contribuye a evacuar el registro contestatario y autogestionador inicialmente predominante en los discursos sobre los "barrios", para redefinir la acción de los profesionales de la Política de la Ciudad como una manera de "encuadrar" las demandas de los habitantes ${ }^{13}$.

\section{Una política encuadrada del "vínculo social"}

Este "encuadre" se explica también debido a los objetos en juego locales y, en particular, municipales, de la Política de la Ciudad. En efecto, es a esta escala donde los equipos de la Política de la Ciudad van a estar encargados de poner en marcha, concretamente, una política de "vínculo social". Para ello, van a procurar movilizar a los habitantes, invitarles a reuniones de concertación o a las de los Consejos de barrios. Van a distribuir subvenciones a asociaciones asentadas en el barrio, o también organizar diversos eventos como mercadillos de antigüedades, comidas de barrio, todo ello con el fin de reanudar el "vínculo social" entre los habitantes. De hecho, en más de 400 municipios a lo largo de los años 1980, la categoría de "barrio sensible" y la retórica que la acompaña, van a ser integradas en la acción municipal. Influyen varias razones para ello: la Política de la Ciudad es fuente de créditos

${ }^{13}$ Ver, por ejemplo la obra destinada a los jefes de proyectos, impulsores de esta política en los municipios (Bonetti, Conan y Allen, 1991). 
suplementarios para rehabilitar las viviendas de protección oficial [HLM]; se presenta también como portadora de recursos, en particular en términos de personal de apoyo, para evitar los "disturbios", cuyo recuerdo obsesiona las mentes al principio de los años 1990, después de los de Vaulx-en-Velin, Sartrouville o Mantes-la-Jolie.

Pero también hay que ver en el entusiasmo por los dispositivos de "democracia local" y el tratamiento "territorializado" de los problemas — garantía de "proximidad"-, una pieza esencial en la estrategia llevada a cabo por numerosos concejales para luchar contra el descrédito que les afecta de manera creciente al final de los años 1980. La inversión en estas temáticas pretende colmar la distancia cada vez más insalvable entre la clase política y los ciudadanos, y más particularmente, las clases populares. Este abismo, alimentado por los escándalos de las "corruptelas" ["affaires"], se explica también por las mutaciones de los partidos de izquierda, especialmente las que se dan en los ayuntamientos comunistas. En Montreuil, por ejemplo, ciudad de los suburbios parisinos dirigida por un alcalde comunista desde los años 1930, la municipalidad debe hacer frente a un fuerte declive del partido comunista a partir de los años 1980. En este municipio de la Seine-St-Denis, el hecho de desarrollar una política de "proximidad" está verdaderamente percibido, al principio de los años 1990, como un medio para recuperar la confianza de los habitantes, así como su voto. La "ciudadanía" va a constituir el cimiento para un discurso alternativo al marxista, mientras que el alcalde, que se aleja del partido comunista, intenta convertir los lugares de la "democracia participativa" - como los consejos de barrios- en las bases de una red que sustituya a la de las células y asociaciones comunistas en declive. La "participación" que los servicios de la Política de la Ciudad intentan promover se convierte así en una prioridad a pesar de que dicha participación sea objeto de una definición y de un estrecho encuadramiento. Es lo que enseña un reportaje del boletín municipal editado entre mayo y noviembre del 1994, que presenta el servicio de la Política de la Ciudad recientemente creado.

En la presentación que se hace de los diferentes barrios llamados sensibles de los que el servicio va a ocuparse y de los problemas a resolver, a la vez se invocan de antemano la ausencia de equipamientos y la urgencia de la rehabilitación de las barriadas HLM. Pero lo que está en juego, como explica el boletín publicado por el municipio, va más allá de la simple mejora de las condiciones de vida materiales. O más bien, dicha mejora depende de otra: la modificación del 'estado anímico' del barrio mediante la organización de reuniones y de momentos susceptibles de (re) suscitar la participación y el encuentro de los habitantes en torno a un proyecto en el que puedan sentirse coparticipes. Un asesor que realiza para la ciudad un estudio sobre uno de los barrios incluidos en la "Política de la Ciudad", y a quien se entrevista en dicho reportaje, lo expresa claramente: "En estas condiciones, sería casi inútil lanzar grandes obras de remodelación de los lugares degradados antes de haber acabado de recrear estos vínculos sociales" (Montreuil-Dépêche, 1994: 149). La Política de la Ciudad se construye así en base a este presupuesto: el marco de vida y la organización social constituyen un único y mismo problema.

La estrecha asociación entre ambas temáticas no deja de tener consecuencias. Lleva primero a excluir de la definición del "problema de los barrios" un cierto 
número de otros problemas. Como explica claramente una concejala, entrevistada en el boletín municipal:

\begin{abstract}
"este barrio es un ejemplo de la complementariedad entre la intervención urbana y la intervención social. Vivir en una barriada [cité] no se limita a ocuparse de lo construido (..): no podemos arreglar los grandes problemas como el del paro, pero podemos ayudar el desarrollo y el florecimiento de las relaciones sociales. Hay que volver a tejer los vínculos entre los habitantes" (Montreuil-Dépêche, 1993).
\end{abstract}

La exclusión del paro de la lista de problemas susceptibles de ser tratados está explícitamente afirmada. Se ve así claramente la relación entre la focalización sobre el "vínculo social" y la remodelación del Estado de bienestar, al reordenar directamente la Política de la Ciudad las prioridades de la acción pública.

Lo que desaparece de los discursos públicos, no es únicamente una acción voluntarista contra el paro. La Política de la Ciudad participa también en el declive del comunismo municipal, concebido como una política voluntarista de construcción (especialmente de viviendas y de equipamientos) encaminada a garantizar a las clases populares el acceso a la ciudad moderna ${ }^{14}$. Pero el giro dado por la Política de la Ciudad señala también el final de las iniciativas en las que han podido involucrarse sus primeros impulsores, es decir acciones basadas en las reivindicaciones de los habitantes y destinadas en ciertas ciudades a renovar una vida política marcada por el dominio a veces poco democrático del partido comunista: ya sean las luchas en contra de la destrucción planificada de barrios de los centros urbanos, sustituidos por el urbanismo de las torres, de las barreras y de las losas, o ya sea mediante un trabajo junto con los habitantes de barrios de viviendas sociales para protestar contra la falta de equipamiento en los grandes conjuntos urbanísticos, tal como pudieron hacerlo los equipos municipales de la Política de la Ciudad durante la primera mitad de los años 1980. Sin embargo - lejos de este tipo de acción - en el reportaje del boletín municipal de Montreuil editado en 1994, se presenta a los miembros del equipo de la Política de la Ciudad como profesionales que actúan de tal modo que unas personas que ya no se hablan van poco a poco a encontrarse, comunicarse $y$, finalmente, a reconciliarse. Los eventos organizados por los jefes de proyecto se parecen a una acción terapéutica, los habitantes aparecen mediante la figura de "enfermo" más que como sujetos políticos. Una vocal explica: "Ciertos habitantes se sienten abandonados, sobre todo en Bel Air, necesitan recobrar confianza en sí mismos, y en las instituciones"(Montreuil-Dépêche, 1994: 151).

La psicologización de "los problemas" de los habitantes acaba así despolitizando de antemano la participación que propicia simultáneamente el Ayuntamiento. Dicha despolitización está reforzada por la imagen que se da de los barrios. Los cuatro barrios objetivo de la Política de la Ciudad están en efecto señalados como espacios "neutros", en los cuales todo habitante, cualquiera sea su origen, puede fundirse, pues aquellos generan "naturalmente" sociabilidad y un sentimiento común de

${ }^{14}$ Sobre las transformaciones del comunismo municipal, véase la encuesta de Bacqué y Fol (1997) en St Denis. 
pertenencia, y son fuente de solidaridad y de intercambios. Al colocarse en un registro psicologizante, al insistir en el consenso que produce el espacio del "barrio", la doctrina de la Política de la Ciudad silencia cualquier dimensión conflictual, entre los habitantes o entre éstos y las instituciones, en provecho de un llamamiento a la buena voluntad general y a las iniciativas consensuales. La política de "participación", impulsada inicialmente por los defensores de la Política de la Ciudad, es decir una política autónoma y reivindicativa, está así profundamente re-encuadrada, y los habitantes invitados a participar en ello están cuidadosamente seleccionados.

La prudencia con la cual se alienta la participación de los habitantes es tanto mayor en cuanto que - como en aquella ciudad con una alta tasa de vivienda social, donde en 1992 un joven de una barriada [cité] fue abatido por un comerciante-, el miedo a los disturbios es muy fuerte. Dicho miedo, así como la gran desconfianza de los ayuntamientos de izquierda con respecto a los "militantes de barriadas" procedentes a menudo de la inmigración magrebí (Masclet, 2004), tienen muchas consecuencias. Primero, la insistencia en los orígenes más que en el estatus social de los habitantes de los barrios populares, en vez de ser una ocasión para subrayar la situación específica de las poblaciones provenientes de la inmigración post-colonial, va a contribuir finalmente a hacerlas aparecer como poblaciones "peligrosas". Y de hecho, si los criterios de edad y de origen vienen a sustituir, en los artículos del boletín municipal, al de la categoría socio-profesional (la palabra "obrero" está casi ausente), los "inmigrados" y los "jóvenes" están evocados sobre todo como fuentes de "problemas" para las demás personas del barrio. El fuerte distanciamiento con respecto a los "jóvenes procedentes de la inmigración" explica también que la política de la participación que se pone en marcha haya llegado a excluir cualquier expresión demasiado contestataria y demasiado violenta de los problemas encontrados por los habitantes, y en particular por los "jóvenes" ${ }^{15}$. Lo atestigua el discurso municipal de Montreuil, que se despliega así en torno a una doble imagen de los jóvenes, marcando una frontera entre los comportamientos negativos (la delincuencia y la revuelta) y los que están valorizados (la acción ciudadana en favor de la paz social). Los periodistas del boletín municipal valoran por ejemplo el compromiso colectivo, a condición de que sea moderado, "positivo", enfocado hacia el espacio del barrio, y que demuestre una voluntad de "integración" pacífica en la vida política e institucional existente. Después de haber abordado los problemas planteados por los jóvenes, un artículo dentro del mismo reportaje salido en 1994 continua así:

Sin embargo, los jóvenes del barrio han demostrado miles de veces su creatividad o su solidaridad. Después del asesinato de un joven hace dos años, los "hermanos mayores" han recorrido las calles del barrio, discutido con los más jóvenes, exhortándoles a no perder la calma. Otros han organizado campañas en favor de los derechos cívicos, animando a sus hermanos pequeños a inscribirse en las listas

${ }^{15}$ Sobre la emergencia de esta retórica sobre la "democracia local” y la selección de los discursos y de los locutores en el seno de dispositivos como los consejos de barrio, ver también Koebel (2006). En el caso de Montreuil, véase el pasaje dedicado al funcionamiento del consejo de barrio en Tissot (2007). 
electorales. Un grupo de adolescentes ha recientemente organizado un debate sobre el código de la nacionalidad... Ahora, unos jóvenes preparan un "viaje para la paz" a Oriente-próximo. (Montreuil-Dépêche, 1994, 147)

Al circunscribir de este modo lo que corresponde a la "buena" participación, al ocultar unas movilizaciones que podrían cuestionar a las propias instituciones, los ayuntamientos van a mantener el silencio general que reina sobre esta otra realidad de los barrios: el fuerte contencioso entre los jóvenes y la policía. Pues, es precisamente este contencioso, ocultado desde "la revuelta de Vaulx-en-Vélin" de 1990, que parece nuevamente silenciado desde noviembre de 2005, mientras que un idéntico guión está en el origen de ambas "revueltas" al igual que de otras muchas en los años 1990: un (dos en 2005) joven encuentra la muerte después de una persecución o de un altercado con la policía.

Se vislumbra bien aquí el impacto de la manera de pensar, formular y de institucionalizar la cuestión de las “barriadas sensibles”. En 2006 al igual que en 1990, el origen de los acontecimientos ha sido progresivamente encubierto, mediante una idéntica generalización, por comentarios sobre los problemas de los "barrios", concebidos como una entidad homogénea. Hoy en día la tonalidad es más represiva que al inicio de los años 1990, pero siguen incuestionados los presupuestos ligados a la categoría de barriadas sensibles, tal como ésta se ha impuesto hace quince años: focalización sobre la cuestión del "vínculo social", percepción de los forasteros y de sus hijos como población "con problemas" e, incluso, amenazante, ocultación de los mecanismos estructurales y, en particular económicos de la segregación, y el rechazo de la cuestión del paro, de la precariedad, de las discriminaciones y, más aún, de la represión policial. La rapidez y el consenso con los que este análisis ha sido retomado en noviembre 2005 muestran la fuerza de los efectos sociales ligados a una categoría. Por ello es importante restituir su génesis, y subrayar cómo la focalización sobre las "barriadas sensibles" no traduce (o no únicamente) una toma de conciencia de los problemas reales; indica sobre todo un movimiento, en profundidad, de refundación del Estado social, recentrado a la vez sobre unos territorios estrechamente circunscritos y sobre unos problemas cuidadosamente seleccionados.

\section{Traducción: Marie José Devillard}

\section{Referencias bibliográficas}

\section{BOURDIEU, Pierre}

1993 "La démission de l'État", en Pierre Bourdieu (Dir.) La misère du monde. Paris: Le Seuil.

BACHMANN,Christian; LEGUENNEC, Nicole

1996 Violences urbaines. Ascension et chute des classes moyennes à travers cinquante ans de Politique de la ville. Paris: Albin Michel, 283-296.

BLUMER Herbert

1971 "Social problems as Collective Behavior", Social problems 18: 278-306. 
BONETTI, Michel; CONAN, Miche; ALLEN, Barbara

1991 Développemnt social urbain, stratégies et méthodes. Paris: L’Harmattan.

COING Henri; TOPALOV, Christian

1996 “Crise, urgence et mémoire. Où sont les vraies ruptures?”, en François Asher, Le logement en question: l'habitat dans les années 1990: continuité et ruptures, La Tour d'Algues: Éditions de l'Aube, 271-291.

DREYFUS François

2000 L'invention de la bureaucratie. Servir l'État en France, en Grande Bretagne et aux États-Unis (XVIII-XX $X^{o}$ siècle), Paris: La Découverte.

DUBEDOUT, Hubert

1983 Ensemble, refaire la ville (rapport au Premier ministre). Paris: La documentation française.

FASSIN Didier

1996 "Exclusion, underclass, marginalidad. Figures contemporaines de la pauvreté urbaine en France, aux États-Unis et en Amérique latine", Revue française de sociologie, XXXVII: 37-77.

JOBERT, Bruno

1994 Le tournant néo-liberal en Europe. Paris: L'Harmattan.

1993 Montreuil-depêche.

1994 Montreuil-depêche.

KOEBEL, Michel

2006 Le pouvoir local ou la démocratie improbable. Broissieux: Éditions du Croquant.

MASCLET, Olivier

2004 La gauche et les cités, enquête sur un rendez-vous manqué. Paris: La dispute.

SIBLOT, Yasmine

2003 Paperasse, guichets et modernisation de l'accueil. Les rapports politiques entre classes populaires et administrations. Thèse de doctorat de sciences sociales. École des Hautes Études en Sciences Sociales.

SPENLEHAUER, Vincent

1998 L'évaluation des politiques publiques, avatar de la planification. (Thèse de doctorat de science politique, Université de Grenoble II.

TISSOT Sylvie

2005 "Reconversions dans la politique de la ville: l'engagement pour les quartiers" Politix: 71-88.

2007 L'état des quartiers. Genèse d'une catégorie d'action publique. Paris: le Seuil.

VIVERET, Patrick

1989 L'évaluation des politiques et des actions publiques. Paris: La découverte. 